\title{
Inherited Cryptic Translocation t(12;17)(q24.3;p13.3) Causing Recurrence of Miller-Dieker Syndrome
}

\author{
Elenice Ferreira Bastos ${ }^{1}$, Carlos Roberto da Fonseca ${ }^{1}$, Ingrid Bendas Feres Lima ${ }^{1}$, \\ Maria de Jesus Esteves Camilo², Kleber da Silva Figueiredo ${ }^{3}$, Anna Luiza Vaz Serrão ${ }^{1}$, \\ Sara Fabíola da Silva Oliveira ${ }^{1}$, Lucia de Fatima Marques de Moraes ${ }^{1}$, Juan Clinton Llerena Jr. ${ }^{4}$ \\ ${ }^{1}$ Clinical Cytogenetic Laboratory, Fernandes Figueira Institute, Oswaldo Cruz Foundation (FIOCRUZ), Rio de Janeiro, Brazil \\ ${ }^{2}$ Maternity School, Federal University of Rio de Janeiro (UFRJ), Rio de Janeiro, Brazil \\ ${ }^{3}$ Biofisical Institute Carlos Chagas Filho, Federal University of Rio de Janeiro (UFRJ), Rio de Janeiro, Brazil \\ ${ }^{4}$ Medical Genetic Department, Fernandes Figueira Institute, Oswaldo Cruz Foundation (FIOCRUZ), Rio de Janeiro, Brazil
}

Email address:

elenice.bastos@iff.fiocruz.br(E. F. Bastos)

\section{To cite this article:}

Elenice Ferreira Bastos, Carlos Roberto da Fonseca, Ingrid Bendas Feres Lima, Maria de Jesus Esteves Camilo, Kleber da Silva Figueiredo, Anna Luiza Vaz Serrão, Sara Fabíola da Silva Oliveira, Lucia de Fatima Marques de Moraes, Juan Clinton Llerena Jr. Inherited Cryptic Translocation t(12;17)(q24.3;p13.3) Causing Recurrence of Miller-Dieker Syndrome. International Journal of Genetics and Genomics. Vol. 7, No. 3, 2019, pp. 50-54. doi: 10.11648/j.ijgg.20190703.12

Received: May 17, 2019; Accepted: June 26, 2019; Published: July 31, 2019

\begin{abstract}
The Miller-Dieker syndrome (MDS) is a severe neurological disorder characterized by lissencephaly, facial dysmorphies, global developmental delay and severe seizures. A deletion at 17p13.3, including the lissencephaly gene (LIS1), is usually present as part of a contiguous gene syndrome. Around $20 \%$ of case LSI1 gene is resulting from inherited balanced translocation. We present the case of a family with cryptic $\mathrm{t}(12 ; 17)$ translocation identified by FISH in two generations. The proband had clinical features of MDS. The parents reported a paternal aunt deceased as a young infant due to "uncontrolled seizures and severe developmental delay. The GTG analysis of proband suggested deletion at $17 \mathrm{p} 13.3$ that was confirmed by FISH. The parental investigation by FISH revealed a paternal translocation involving regions $12 q$ ter and $17 \mathrm{p} 13.3$. This familial chromosomal rearrangement associated to MDS has modified the genetic counseling of the couple. From a very low risk of recurrence on the cases associated to a de novo del17p13.3, to a much higher risk, since it was associated to a familial translocation. This risk of recurrence, considering meiotic segregation of balanced translocation involving the 17p13.3 region is relatively high $(12 \%)$ which alone would justify prenatal diagnosis. Classical and molecular cytogenetic investigations in the fetal sample were normal reassuring the couple as to a normal baby with neither $17 \mathrm{p} 13.3$ deletion nor carrier of the paternal translocation. This rare case identified by FISH demonstrate the need of providing molecular cytogenetic analysis for other family members; since, criptical balanced rearrangements may segregate undetected. This case evidences the importance of molecular study of parents of children with microdeletions, which could considerably improve the certainties regarding genetic counseling.
\end{abstract}

Keywords: Miller Dieker Syndrome, Cryptic Translocation, Microdeletion, Prenatal Diagnosis, Genetic Couseling

\section{Introduction}

Miller-Dieker syndrome (MDS), or chromosome 17p13.3 deletion syndrome is characterized by classic lissencephaly, microcephaly, wrinkled skin over the glabella and frontal suture, prominent occiput, narrow forehead, downward slanting palpebral fissures, small nose and chin, growth retardation, and mental deficiency with severe seizures and
EEG abnormalities. Life expectancy is drastically reduced, with death most often occurring during early childhood (OMIM, 247200).

The LIS1 gene was cloned from the lissencephaly critical region at $17 \mathrm{p} 13.3$ in 1993 been confirmed as the cause of lissencephaly in 1997 [1]. The major facial anomalies typical of MDS are presumed to result from deletion of additional genes 200-300 kb telomeric to this locus [2, 3], 
characterizing an example of contiguous gene syndrome. However, about $90 \%$ of MDS cases have a visible chromosomal deletion at $17 \mathrm{p} 13.3$. These deletions are submicroscopic only detect by in situ hibridization [4].

Microdeletions in $17 \mathrm{p} 13.3$ may occur as sporadic or inherited events due to the presence of balanced rearrangements (especially translocations) of one parent. Pollin et al reported 14 families with chromosomal unbalanced offspring known to segregate with balanced reciprocal translocations involving $17 \mathrm{p} 13.3$ and another autosome. The risk of recurrence of viable and unbalanced offspring in at least the second trimester of pregnancy was about $26 \%$ in these families and MDS appears to be the greatest risk. However, in cases of cryptic translocations in a parent the recurrent risk for future pregnancies modifies considerable [5].

Here, we report the cytogenetic investigation of a family in which a balanced paternal cryptic translocation $(12 ; 17)$ (q24.3; p13.3) was detected by FISH only after diagnosis of MDS in a first baby. This finding significantly increases the risk of recurrence of MDS in this family. A prenatal cytogenetic investigation in the next pregnancy identified a normal female karyotype.

\section{Case Report}

The proband had a typical lisencephaly clinically diagnosed by a TC scan (Figure 1A). Non-consanguineous parents, GESTA II, Ab I, 29 years old mother and a 31 years old father. Severe convulsions and low birth weight. In prenatal period, an ultrassound revealed a dilated cerebral ventricule. He was born weighting $1,745 \mathrm{~g}$ for 34 weeks gestations, and measuring $44 \mathrm{~cm}$ in length. Low Apgar score due to absence of crying and neonatal asphyxia. Very hypotonic with a coarse face. The patient deceased at 07 months of age due to respiratory insufficiency, cardiogenic shock and sepsis. No post-mortem examination was performed. The Family history revealed that a paternal aunt deceased at 21 months of life with hypotonia and brain malformation.
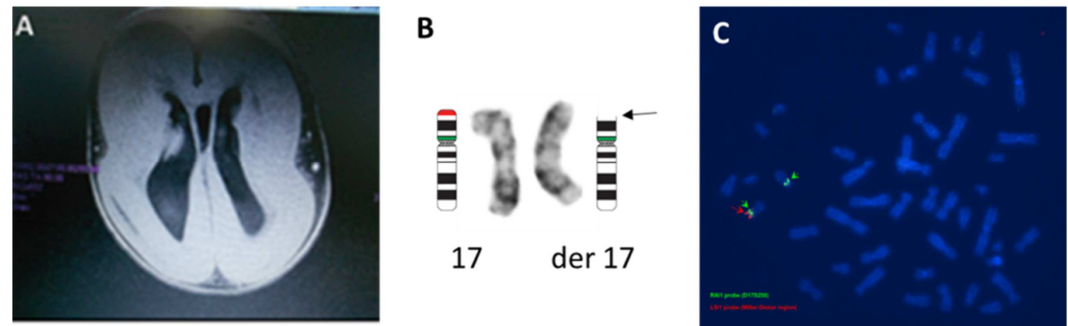

Figure 1. A) Type I lyssencephaly from the index case. B) Partial GTG karyotype and ideogram of the index case. C) FISH analysis with LSI1/RAII probe, showing loss of red signal (17p13.3 deletion).
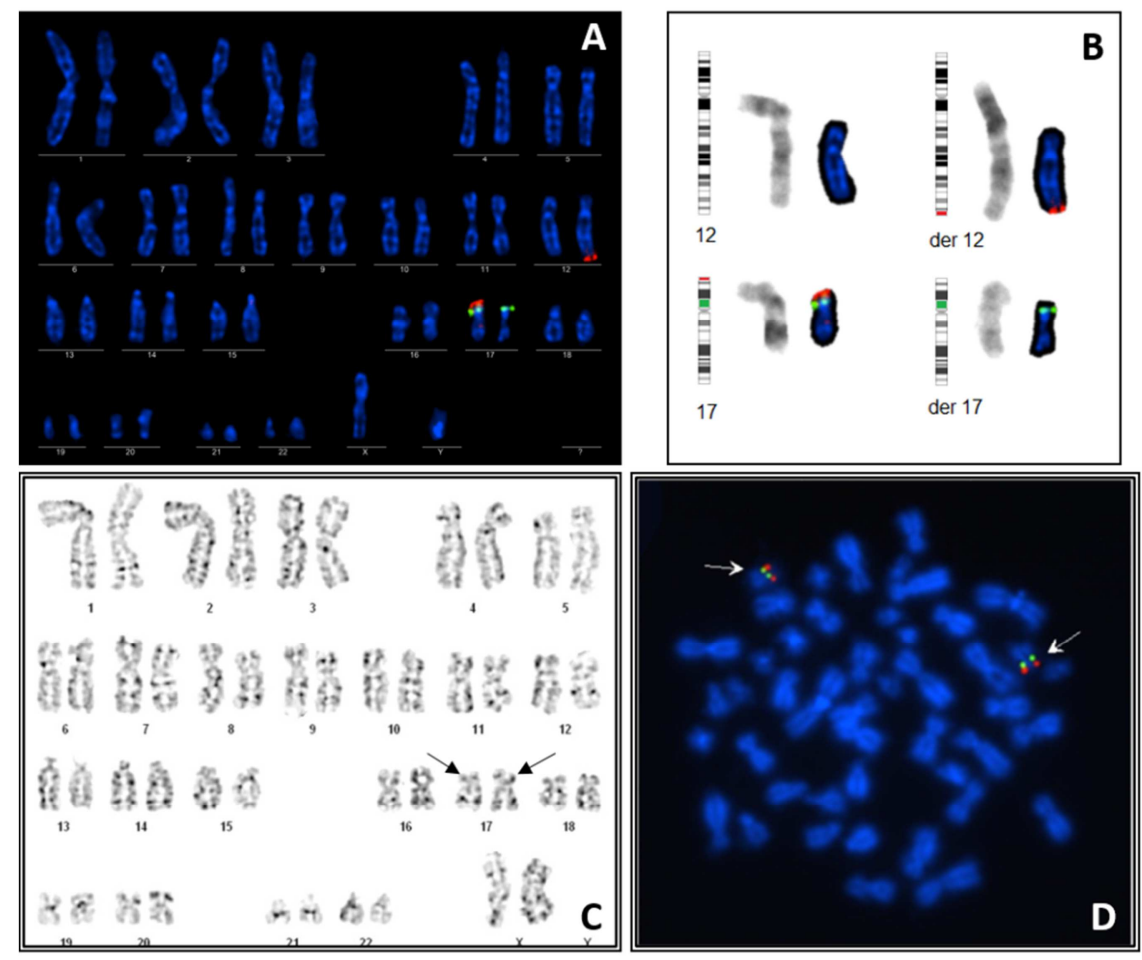

Figure 2. A) FISH analysis on paternal chromosomes using LSI1/RAI1 probe showing the cryptic balanced translocation involving 17p13.3 region. B) Paternal partial karyotype by GTG banding, FISH and ideogram with affected region. C) GTG band in fetal amount (CVS direct preparation) - 46,XX D) FISH showing both red and green signals characterizing integrity of 17p13.3 region. Fetal karyotype: 46,XX.ish (17p13.3)(LISIx2). 
GTG-banded karyotype of the proband was apparently normal, but FISH analysis with LS1/RAI1 probe showed only one red signal at the short arm one of the chromosome 17 , identifying a microdeletion at $17 \mathrm{p} 13.3$ confirming MillerDieker syndrome diagnosis (Figure $1 \mathrm{~b}$ and $1 \mathrm{c}$ ).

The parents's karyotypes by GTG banding were normal, but the history of a paternal aunt with similar phenotype of lissencephaly, a possible familial case of MDS was considered. FISH investigation of the parents revealed a paternal cryptic balanced translocation envolving $17 \mathrm{p} 13.3$ region and the long arm of chromosome 12 (12q ter) (Figures 2A e 2B).

\section{Methods}

The proband's cytogenetic study was performed from peripheral blood sample stimulated by phytohemaglutinin. For prenatal diagnosis, the chromosomes from chorionic villous sample were obtain by direct method according to standard protocol. The cytogenetic analysis in both samples was carried out after GTG banding (450 bands per haploid set) and classification according to ISCN 2016 [6]. FISH analysis was performed according to standard protocol using LIS1/RAI1 probe.

\section{Discussion}

Lyssencephaly (LIS) is characterized by a smooth or nearly smooth brain surface and a shortage of gyrus and sulcal development, encompassing a spectrum of malformations of the brain surface ranging from complete agyria to subcortical band heterotopia (SBH) [1].

Classical Lissencephaly (type I) is a cerebral malformation caused by abnormal neuronal migration at 9 to 13 weeks of gestation, resulting in a spectrum of agyria, agyria / pachygria and pachygria malformations. It is characterized by an abnormally thick and poorly organized cortex, with 4 primitive layers, diffuse neuronal heterotopia, enlarged and dysmorphic ventricles, and often hypoplasia of the corpus callosum [7]. It is a genetically heterogeneous disorder. Five major different genes are known to cause human lissencephaly: LIS1 or PAFAH1B1, 14-3-3-epsilon (YWHAE), DCX, RELN and ARX [8, 9].

Miller-Dieker Syndrome (MDLS) corresponds to a microdeletion syndrome of contiguous genes involving the 17 p13 chromosome and including the genes PAFAH1B1 and YWHAE [6]. Lissencephaly caused by mutations in the PAFAH1B1 gene is also called "isolated" lysencephaly to distinguish it from the form associated with other traits that accompany MDS. Most patients with classic lissencephaly have deletions in the LIS1 gene. Cardoso et al, found that 65 of 98 patients with isolated lissencephaly or MLDS had large deletions of the LIS1 gene [9]. Among 41 intragenic mutations of LIS1, $36(88 \%)$ resulted in either a truncated or internally deleted protein. Only $5(12 \%)$ of the 41 were missense mutations. Mutations occurred throughout the gene, except in exon 7 [9].

Cardoso et al, 2003, completed a physical and transcriptional map of the $17 \mathrm{p} 13.3$ region of LIS1 from the telomere. Using FISH, they mapped the size of the deletion in 19 children with ILS, 11 children with MDS, and 4 children with $17 \mathrm{p} 13.3$ deletions not involving LIS1. They showed that the critical region that differentiates ILS from SMD at the molecular level can be reduced to $400 \mathrm{~kb}$. Overall, small genomic deletions / duplications accounted for $49 \%$ of all changes identified in LIS1, and involvement of LIS1 was demonstrated in 39 (87\%) of the 45 patients [10].

In general, LIS1 or DCX mutations were found in $60 \%$ of patients, combining with the previously observed frequency of LIS1 mutations detected by FISH. Pilz et al, concluded that these 2 genes account for about $76 \%$ of sporadic lysencephaly [11]. Dobyns et al, 1999 compared the phenotype of 48 children with lysencephaly, including 12 with MDS with large deletions including LIS1, 24 with isolated lissencephaly sequence caused by minor deletions of LIS1 or mutations, and 12 with DCX mutations [1]. There were consistent differences in cerebral giral patterns, with LIS1 mutations associated with more severe malformations in late stages of development, and DCX mutations associated with more severe malformations in early stages of development.

Deletions involving 17 p13.3 can often be detected by classical cytogenetic analysis (GTG banding, with a resolution of 550 bands per haploid set) or by high resolution ( 800 bands per haploid set). However, many of these changes are only visualized by fluorescence in situ hybridization (FISH) technique. Large deletions can also be associated with other changes, such as balanced translocations. Eighty percent of patients have a "de novo" microdeletion in 17 p 13.3 and $20 \%$ inherited deletion from one of the progenitors carrying a balanced chromosomal rearrangement, so the risk of recurrence in cases of "de novo" mutation is negligible, but if one of the parents has a balanced translocation, this risk increase considerably [5, 12].

An important field in medical genetics is genetic counselling that involves the calculation of a personalized risk on individuals to estimate probabilities of having a child with a genetic disorder.

Different chromosomal abnormalities can lead to loss of LIS1 gene, including: deletion, ring chromosome formation or inheritance unbalanced translocation involving the 17p13.3. Approximately $80 \%$ of individuals with MDS have a de novo deletion involving $17 \mathrm{p} 13.3$. The remainder corresponds to loss of the inherited LSI1 gene as result of a parental balanced translocation $[12,13]$. There are reports of translocations involving different chromosomes with the 17 p13.3 region, however this is the second case involving chromosomes 12 and 17 . The majority of these patients has, besides the characteristics of the MDS, additional phenotypic abnormalities, as consequence of a partial trisomy of other involved chromosomes [14].

If neither parent has a structural chromosomal 
rearrangement detectable by high resolution chromosome analysis, the risk to siblings is insignificante, not neglecting to consider the rare occurrence of germinal mosaicism. However, the identification of a familial chromosomal rearrangement associated to MDS modified the genetic counseling: from a very low risk of recurrence on the cases associated to de novo cytogenetic abnormality to a higher risk once associated to a familial translocation. The risk of recurrence, considering meiotic segregation of balanced translocation involving the $17 \mathrm{p} 13.3$ region is relatively high $(12 \%)$ which alone would justify prenatal diagnosis (Figure 3) $[15]$.

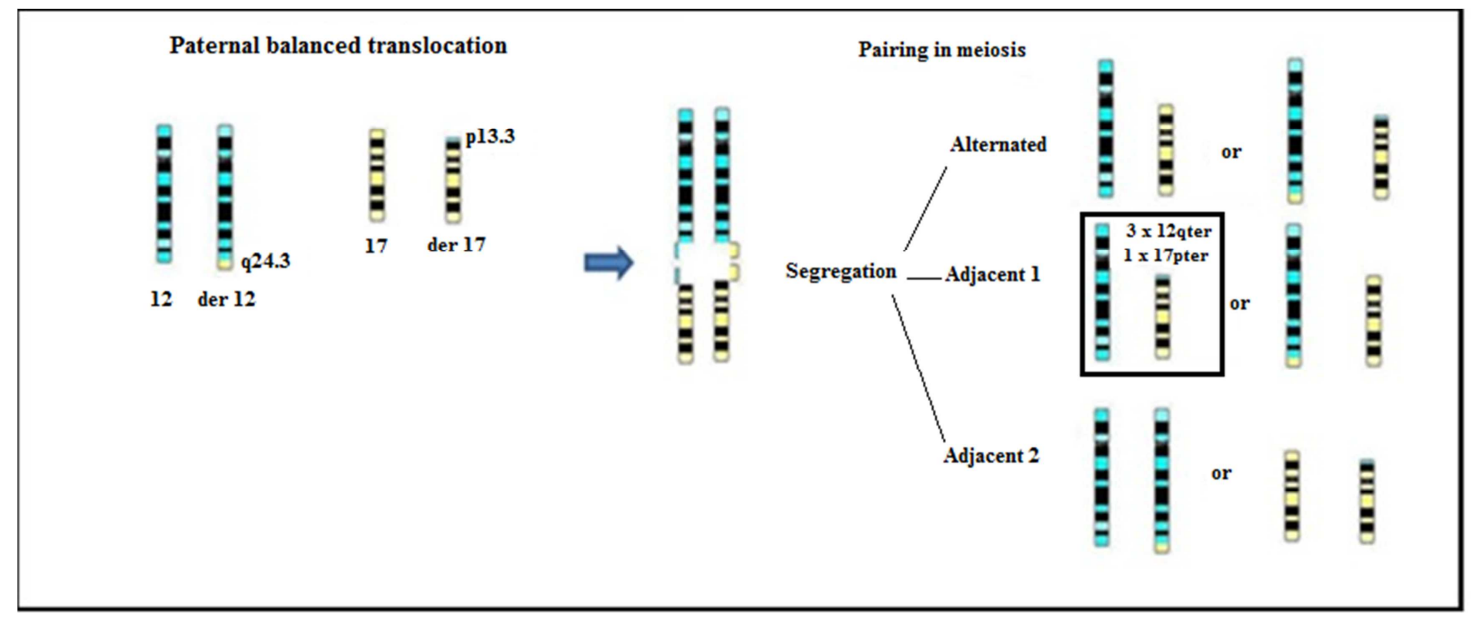

Figure 3. Diagram of the paternal balanced translocation between chromosomes 12 and 17, t(12q24.32;17p13.3). A quadrivalent formation in meiosis and adjacent 1 segregation leading to unbalanced gamete ( $3 \times 12$ qter and monosomy of 17 pter, including the p13.3 region) occured in our patient.

In this case, cytogenetic analysis by GTG banding showed normal karyotype and only the FISH technique was able to detect balanced paternal translocation. With this information, it was possible to carry out the most reliable family counseling. We studied the fetal sample of the next pregnancy whose classical and molecular cytogenetic investigations were normal, reassuring the couple as to a normal baby with either $17 \mathrm{p} 13.3$ deletion or carrier of the paternal translocation (Figures 2C e 2D).

\section{Conclusion}

Currently, the first line diagnosis for patients with lissencephaly and for most genetic conditions associated with microdeletions and / or microduplications has been comparative genomic hybridization (high resolution array $\mathrm{CGH}$ ) or fluorescence in situ hybridization (FISH) being the genetic diagnosis increasingly directed to the presented clinical features. Our case corresponds to one of the few reports of MDS as a consequence of a familial balanced translocation and the second involving chromosomes 12 and 17. Like in the previous report, this translocation was only detected by FISH, which was performed due to a previous history of recurrent lissencephaly. These cryptic events significantly change the criteria for family genetic counseling beyond prenatal genetic diagnosis, since the loss of $17 \mathrm{p}$ in the proband is not considered a de novo deletion. From this new rare case of balanced familial translocation associated with lissencephaly, together with literature reports, we have highlighted the need to provide a broader analysis, using a combination of cytogenetic and molecular methods, not only for the diagnosis of the patient, but also for all members of the family, as these cryptic rearrangements can segregate and never be identified unless family history is described in detail.

\section{References}

[1] Reiner O, Carrozzo R, Shen Y et al. Isolation of a Miller Dieker lissencephaly gene containing $G$ protein beta subunit - like repeats. Nature 1993: 364: 717-721.

[2] Dobyns, W. B., Truwit, C. L., Ross, M. E., Matsumoto, N., Pilz, D. T., Ledbetter, D. H., Gleeson, J. G., Walsh, C. A., Barkovich, A. J. Differences in the gyral pattern distinguish chromosome 17-linked and X-linked lissencephaly. Neurology 1999; 53: 270-277.

[3] Chong SS, Pack SD, Roschke AV, Tanigami A, Carrozzo R, Smith AC, Dobyns WB, Ledbetter DH. A revision of the lissencephaly and Miller-Dieker syndrome critical regions in chromosome 17p13.3. Hum Mol Genet 1997; 6: 147-155.

[4] Lo Nigro, C., Chong, S. S., Smith, A. C. M., Dobyns, W. B., Carrozzo, R., Ledbetter, D. H. Point mutations and an intragenic deletion in LIS1, the lissencephaly causative gene in isolated lissencephaly sequence and Miller-Dieker syndrome. Hum. Molec. Genet. 1997; 6: 157-164. Blazejewski SM, Bennison SA, Smith TH and Toyo-oka K. Neurodevelopmental Genetic Diseases Associated With Microdeletions and Microduplications of Chromosome 17p13.3. Front. Genet 2018; 9: 80.

[5] Pollin, T. I., Dobyns, W. B., Crowe, C. A., Ledbetter, D. H., Bailey-Wilson, J. E., Smith, A. C. M. Risk of abnormal pregnancy outcome in carriers of balanced reciprocal translocations involving the Miller-Dieker syndrome (MDS) critical region in chromosome 17p13.3. Am. J. Med. Genet 1999; 85: 369-375.

[6] Shaffer, L. G. et al. An International System for Human Cytogenetic Nomenclature. Basel: Karger 20132016. 
[7] Kato, M., Dobyns, W. B. Lissencephaly and the molecular basis of neuronal migration. Hum. Molec. Genet. 12 (R1) 2003; R89-R96.

[8] Fry AE, Cushion TD, Pilz DT. The genetics of lissencephaly. Am J Med Genet Part C Semin Med Genet, 2014, 166C: 198210.

[9] Cardoso, C., Leventer, R. J., Dowling, J. J., Ward, H. L., Chung, J., Petras, K. S., Roseberry, J. A., Weiss, A. M., Das, S., Martin, C. L., Pilz, D. T., Dobyns, W. B., Ledbetter, D. H. Clinical and molecular basis of classical lissencephaly: mutations in the LIS1 gene (PAFAH1B1). Hum. Mutat 2002; 19: 4-15.

[10] Cardoso, C., Leventer, R. J., Ward, H. L., Toyo-oka, K., Chung, J., Gross, A., Martin, C. L., Allanson, J., Pilz, D. T., Olney, A. H., Mutchinick, O. M., Hirotsune, S., WynshawBoris, A., Dobyns, W. B., Ledbetter, D. H. Refinement of a 400-kb critical region allows genotypic differentiation between isolated lissencephaly, Miller-Dieker syndrome, and other phenotypes secondary to deletions of $17 \mathrm{p} 13.3$. Am. J. Hum. Genet 2003; 72: 918-930.

[11] Pilz, D. T., Matsumoto, N., Minnerath, S., Mills, P., Gleeson, J. G., Allen, K. M., Walsh, C. A., Barkovich, A. J., Dobyns,
W. B., Ledbetter, D. H., Ross, M. E. LIS1 and XLIS (DCX) mutations cause most classical lissencephaly, but different patterns of malformation. Hum. Molec. Genet. 7 1998; 20292037.

[12] Thomas MA, Duncan AM, Bardin C, Kaloustian VM. Lissencephaly with $\operatorname{der}(17) \mathrm{t}(17 ; 20)(\mathrm{p} 13.3 ; \mathrm{p} 12.2)$ mat. Am J Med Genet A 2004; 124A: 292-5.

[13] Van Zelderen-Bhola SL, Breslau-Siderius EJ, Beverstock GC, Stolte-Dijkstra I, de Vries LS, Stoutenbeek P, et al. Prenatal and postnatal investigation of a case with Miller-Dieker syndrome due to a familial cryptic translocation $t(17 ; 20)$ (p13.3; q13.3) detected by fluorescence in situ hybridization. Prenat Diagn 1997; 17: 173-9.

[14] Grosso S, Fichera M, Galesi O, Luciano D, Pucci L, Giardini $\mathrm{F}$, et al. Bilateral periventricular nodular heterotopia and lissencephaly in an infant with unbalanced $\mathrm{t}(12 ; 17)$ (q24.31; p13.3) translocation. Dev Med Child Neurol 2008; 50: 473-6.

[15] Pollin TI, Dobyns WB, Crowe CA, Ledbetter DH, BaileyWilson JE, Smith AC. Risk of abnormal pregnancy outcome in carriers of balanced reciprocal translocations involving the Miller-Dieker syndrome (MDS) critical region in chromosome 17p13.3. Am J Med Genet 1999: 85: 369-375. 